\title{
Hacia una comprensión de la conversión ecológica
}

Mauricio Rincón Andrade Pontificia Universidad Javeriana Colombia

Para citar este artículo: Rincón Andrade, Mauricio. «Hacia una comprensión de la conversión ecológica». Franciscanum 169, Vol. LX (2018): 311-337.

\section{Resumen}

La encíclica Laudato si ' del papa Francisco se ha convertido en uno de los documentos más mediáticos y comentados de la Doctrina Social de la Iglesia. Fundamentalmente porque se acerca de manera crítica y rigurosa a la crisis socio-ambiental por la que estamos pasando Y, además, porque no se queda solo en el análisis, sino porque ofrece algunas líneas de acción a partir de la rica tradición de la Iglesia y de la espiritualidad cristiana. Dentro de las distintas alternativas que ofrece el papa sudamericano en su escrito, en este artículo vamos a proponer un acercamiento a una específica: la «conversión ecológica», principalmente porque es un llamado a optar por otro estilo de vida y a cambiar estructuras que rigen nuestra sociedad. 


\title{
Palabras clave
}

Conversión, sistematización, conversión ecológica, nuevo estilo de vida, Laudato si'.

\section{Towards the understanding of the ecological conversion}

\begin{abstract}
The encyclical Laudato si' of Pope Francis has become one of the most broadcasted and commented documents of the Social Doctrine of the Church. Fundamentally because it is a critical and rigorous approach to the socio-environmental crisis that we are going through and, moreover, because it is not only in analysis but also because it offers some lines of action based on the rich tradition of the Church and Of Christian spirituality. Within the different alternatives offered by the South American pope in his writing, in this article we are going to propose an approach to a specific one: the "ecological conversion». Mainly because it is a call to opt for another lifestyle and to change structures that govern our society.
\end{abstract}

\section{Key words}

Conversion, systematization, ecological conversion, new life style, Laudato si'.

\section{Introducción}

Hoy más que nunca somos conscientes que no solo necesitamos reconciliarnos con Dios, con los otros y con nosotros mismos, 
sino que es necesario reconciliarse con «nuestra hermana y madre tierra $»^{1}$. Y para realizar dicha reconciliación es necesario, ante todo, una conversión ecológica. El tema de la conversión ecológica ha entrado a formar parte de la doctrina social de la Iglesia. Fue el papa Juan Pablo II quien tomó este concepto y profundizó en su sentido². Francisco retomó el tema y lo desarrolló en su encíclica sobre el cuidado de la casa común. Los obispos australianos (citados por el papa Francisco en Laudato si') han sabido expresar la conversión en términos de reconciliación con lo creado:

Para realizar esta reconciliación debemos examinar nuestras vidas y reconocer de qué modo ofendemos a la creación de Dios con nuestras acciones y nuestra incapacidad de actuar. Debemos hacer la experiencia de una conversión, de un cambio del corazón ${ }^{3}$.

La sección dedicada a la conversión ecológica la encontramos en la encíclica en el capítulo 6, sin embargo, desde los números iniciales del documento se hace referencia al tema. Esto, por varios motivos, en palabras del cardenal Peter Turkson, Presidente del Pontificio Consejo de Justicia y Paz:

Para indicar desde el principio la causa de la grave crisis ambiental y social: el pecado; en segundo lugar, para ofrecer el remedio verdadero a la situación creada por el pecado: la conversión. Y, finalmente, para

1 Conferencia de los Obispos católicos de Australia, A New Earth - The Environmental Challenge 2002, consultada en marzo 10, 2017, http://www.socialjustice.catholic.org.au/files/SJSandresources/2002_SJSS_statement.pdf.

2 Juan Pablo II, Juan Pablo II, Mensaje para la Jornada Mundial de la Paz de 1990, n. 1, consultada en marzo 10, 2017, https://w2.vatican.va/content/john-paul-ii/es/messages/peace/documents/ hf_jp-ii_mes_19891208_xxiii-world-day-for-peace.html; Audiencia General, miércoles 17 de enero de 2001, n. 3, consultada en marzo 10, 2017, https://w2.vatican.va/content/john-paul-ii/es/ audiences/2001/documents/hf_jp-ii_aud_20010117.html; Juan Pablo II y Bartolomé I, Firma de la Declaración de Venecia, consultada en marzo 10, 2017, https://w2.vatican.va/content/john-paulii/es/speeches/2002/june/documents/hf_jp-ii_spe_20020610_venice-declaration.html y Juan Pablo II, Exhortación apostólica postsinodal Pastores Gregis, n. 70, consultada en marzo 10, 2017, http:// w2.vatican.va/content/john-paul-ii/es/apost_exhortations/documents/hf_jp-ii_exh_20031016_ pastores-gregis.html.

3 Francisco, Carta Encíclica Laudato Si' sobre el cuidado de la casa común, n. 218, consultada en marzo 10, 2017, http://w2.vatican.va/content/francesco/es/encyclicals/documents/papa-francesco_20150524_enciclica-laudato-si.html. 
significar la continuidad con la tradición cristiana y con el magisterio pontificio precedente ${ }^{4}$.

En este artículo me propongo hacer una sistematización de la categoría de la conversión ecológica. El texto está dividido en cuatro apartados. En el primero voy a describir la novedad y la recepción que ha tenido la encíclica Laudato si' del papa Francisco. En el segundo empezaré a desarrollar la sistematización de la categoría recorriendo el tema en el Magisterio de la Iglesia. En el tercer apartado veremos los aportes específicos del papa Francisco en relación con la conversión ecológica. Y, finalmente, presentaré una serie de aspectos prácticos que se desprenden de la comprensión de la categoría.

Resulta muy pertinente realizar esta sistematización de la conversión ecológica porque es un camino que se nos abre a la hora enfrentar los graves problemas ambientales y sociales por los que estamos pasando. En palabras del papa Benedicto XVI: «los desiertos exteriores se multiplican en el mundo porque se han extendido los desiertos interiores $»^{5}$.

\section{Laudato si $^{\prime}$ : novedad y recepción}

La encíclica Laudato si', del papa Francisco, representa un hito en la historia de la Iglesia. Eso por varias razones. En primer lugar, por el tema que aborda: la problemática medioambiental. Es la primera vez que un papa, en un documento de este tipo, trata cuestiones ecológicas. Sin embargo, no se debe entender simplemente como una propuesta que incorpora las preocupaciones medioambientales a la Doctrina Social de la Iglesia, sino que va más allá. Francisco realiza un profundo análisis y señala que en realidad no estamos solo ante

4 Fernando Chica y Carlos Granados, Loado seas mi Señor. Comentario a la encíclica Laudato si' del papa Francisco (Madrid: BAC, 2015), 21.

5 Benedicto XVI, Homilía en el solemne inicio del ministerio petrino, consultada en marzo 10, 2017, https:// w2.vatican.va/content/benedict-xvi/es/homilies/2005/documents/hf_ben-xvi_hom_20050424_iniziopontificato.html. 
una degradación ambiental sino también ante una degradación social: «No hay dos crisis separadas, una ambiental y otra social, sino una sola y compleja crisis socio-ambiental $»^{6}$. Pero no se queda solo en el nivel del análisis, sino que quiere proponer una serie de alternativas a los problemas sociales y ambientales por los que estamos pasando. Y en este nivel propositivo podemos incluir el llamado paradigma de la ecología integral, que para muchos especialistas es uno de los aportes más originales de la encíclica ${ }^{7}$. En segundo lugar, nos encontramos frente al documento más extenso de toda la Doctrina Social de la Iglesia, 41.950 palabras y 172 notas, superando incluso a la constitución Gadium et spes de Vaticano II que tiene 35.111 palabras y 170 notas $^{8}$.

Pero no solo se destaca por su extensión sino por su colegialidad. Junto a las referencias al magisterio de sus predecesores (Benedicto XVI, Juan Pablo II y Pablo VI) y de otros documentos vaticanos, refiere numerosas declaraciones de Conferencias episcopales de todos los continentes: Sudáfrica, Filipinas, Bolivia, Alemania, Argentina, Estados Unidos, Canadá, Japón, Brasil, República Dominicana, Paraguay, Nueva Zelanda, Portugal, México y Australia. Al respecto nos dice Julio Luis Martínez, S.J., rector de la Universidad Pontificia Comillas de Madrid: «aquí hay un importante aspecto eclesiológico en el que la encíclica hace una aportación no menor. Las citas de las declaraciones oficiales de los obispos del mundo no son solo de carácter decorativo, sino que reflejan una convicción honda del papa en el sentido de una eclesiología de la comunión para la cual el obispo de Roma es el servidor de la unidad de las iglesias particulares» ${ }^{9}$.

En tercer lugar, esta encíclica ha tenido un gran impacto mediático y ha sido recibida con entusiasmo por personas y grupos

\footnotetext{
Francisco, Carta Encíclica Laudato Si' sobre el cuidado de la casa común, n. 139.

Cf. Costa y Foglizzo, «L'ecologia integrale», Aggiornamenti Sociali 66 (2015): 541-548.

Ildefonso Camacho, «Laudato si': el clamor de la tierra y el clamor de los pobres. Una encíclica más que ecológica», Revista de Fomento Social 71 (2016): 59-79.

9 Julio Luis Martínez, Laudato si' y la cuestión socio-ambiental. Clamor de la Tierra y de los pobres (Santander: Sal Terrae 2015), 27.
} 
fuera de la Iglesia Católica. Por ejemplo, la revista Nature, una de las publicaciones más reconocidas en el ámbito científico a nivel global le dedicó una editorial con el título: Hope from the Pope ${ }^{10}$ En dicha publicación se elogia el documento papal y se afirma que llega en un momento oportuno y se convierte en una alerta valiosa frente a la crisis ecológica por la cual está pasando el planeta. La revista Science y organismos internacionales como la ONU, la FAO y el Programa de Naciones Unidas para el Medio Ambiente (PNUMA) no solo hicieron eco de Laudato $\mathrm{Si}^{\prime}$, sino que destacaron los importantes aportes que el documento papal hace a problemáticas tan actuales como la degradación del medioambiente y el cambio climático, entre otras.

A partir de su publicación, el 24 de mayo de 2015, la encíclica Laudato si ' ha sido objeto de comentarios y estudios, no solo desde la teología, sino desde otras ramas del saber. Son muchos los temas que se podrían analizar de sus seis capítulos, sin embargo, en este artículo, como decía en la introducción, me voy a centrar en uno específico, la conversión ecológica, dado que afecta a nuestro estilo de vida $y$, en general, a las instituciones que rigen y forman el conjunto de la sociedad.

\section{La conversión ecológica en el Magisterio de la Iglesia}

\subsection{La conversión ecológica}

La conversión dentro de la larga tradición de la Iglesia se ha entendido como un camino de retorno al Padre del cual nos alejamos por el pecado ${ }^{11}$. Es una llamada del mismo Jesús (Mc 1,15). Al respecto escribía Juan Pablo II:

\footnotetext{
10 Nature 522 (25 de junio de 2015): 391, consultada en marzo 10, 2017, http://www.nature.com/news/ hope-from-the-pope-1.17824.

11 Catecismo de la Iglesia Católica, n. 1423, consultada en marzo 10, 2017, http://www.vatican.va/ archive/catechism_sp/index_sp.html.
} 
Siendo el pecado el principio activo de la división -división entre el hombre y el Creador, división en el corazón y en el ser del hombre, división entre los hombres y los grupos humanos, división entre el hombre y la naturaleza creada por Dios-, solo la conversión ante el pecado es capaz de obrar una reconciliación profunda y duradera, donde quiera que haya penetrado la división ${ }^{12}$.

Para Juan Pablo II el pecado causa cuatro divisiones fundamentales:

1. Entre el hombre y el Creador;

2. En el interior del hombre;

3. Entre los hombres y los grupos humanos;

4. Entre el hombre y la naturaleza.

Igualmente, el Patriarca Ecuménico de Constantinopla Bartolomé, muy en consonancia con las divisiones propuestas por Juan Pablo II, nos recuerda que el pecado no solo se reduce a las dimensiones con Dios, con nosotros mismos y con los otros, sino que también se refiere a nuestra relación con la creación:

Que los seres humanos destruyan la diversidad biológica en la creación divina; que los seres humanos degraden la integridad de la tierra y contribuyan al cambio climático, desnudando la tierra de sus bosques naturales o destruyendo sus zonas húmedas; que los seres humanos contaminen las aguas, el suelo, el aire. Todos estos son pecados. ${ }^{13}$

En esta misma línea algunos autores incluso hablan de pecados antiecológicos. Uno de ellos es Leonardo Boff quien en los últimos años ha desarrollado un diálogo muy pródigo entre la teología y la ecología. En uno de sus libros ${ }^{14}$ hace un interesante análisis de lo que él llama pecados capitales antiecológicos referidos a la Amazonía brasilera. En dicho análisis se refiere, en primer lugar, a la inmensa

Juan Pablo II, Exhortación apostólica Postsinodal Reconciliatio et paenitentia, n. 23, consultada en marzo 10, 2017, http://w2.vatican.va/content/john-paul-ii/es/apost_exhortations/documents/hf_jpii_exh_02121984_reconciliatio-et-paenitentia.html.

13 Bartolomé, Discurso en Santa Bárbara, California (8.11.1997), en Francisco, Carta Encíclica Laudato Si' sobre el cuidado de la casa común, n. 8.

14 Cf. Leonardo Boff, Ecología: grito de la tierra, grito de los pobres (Madrid: Trotta 1996), 113-143. 
riqueza de este templo de la biodiversidad del planeta que comprende un área de 6.5 millones de kilómetros cuadrados; $y_{\text {, en segundo lugar, }}$ desarrolla todos los pecados capitales antiecológicos que se están haciendo frente a este santuario de la vida. En palabras de Boff:

La Amazonía es el lugar donde Gaia muestra la exuberante riqueza de su cuerpo. Y también el lugar donde más violencia sufre. Si queremos ver el rostro brutal del sistema capitalista/industrialista, visitemos la Amazonia brasilera. Allí se cometen todos los pecados capitales (a la vez pecados mortales y pecados del capital). Allí se manifiesta sin tapujos el gigantismo del espíritu de la modernidad, lo racionalizado de lo irracional y la lógica diáfana del sistema. Allí queda también patente la clara contradicción entre capitalismo y ecología ${ }^{15}$.

En este inmenso y rico territorio de vida, sigue Boff, se presentan los pecados antiecológicos que los define como aquellas acciones que realizamos en contra de la naturaleza y en contra de millones de especies y muchos pueblos nativos, en donde no solo acabamos con sus vidas, sino que ponemos en riesgo nuestra misma existencia como especie. Siguiendo con su análisis:

El Estado brasilero, las empresas nacionales y las multinacionales han configurado un poderoso trípode. Han dado origen a lo que se ha denominado «el modo de producción amazónico». Este modo se define como una forma de producción deliberadamente depredadora, con aplicación intensiva de la tecnología contra la naturaleza, que declara la guerra a los árboles, extermina poblaciones autóctonas e inmigradas, sobreexplota la fuerza laboral con vistas a la producción para la exportación y suministro del mercado mundial. Más que un modo de producción amazónico, lo que tenemos ante nuestros ojos es un modo de destrucción amazónico ${ }^{16}$.

Frente a estas divisiones causadas por el pecado son necesarias la conversión y la reconciliación. A lo largo de la historia de la Iglesia se ha hecho más hincapié en las tres primeras divisiones, pero en los últimos años se ha tomado conciencia de la necesidad de propender por una conversión de nuestro pecado que daña a nuestra madre tierra como la llamaban los pueblos indígenas. El papa Francisco,

15 Leonardo Boff, Ecología: grito de la tierra, grito de los pobres, 113.

16 Leonardo Boff, Ecología: grito de la tierra, grito de los pobres, 114. 
en la encíclica Laudato si', en relación con la reconciliación con la creación, toma el aporte de la Conferencia de los Obispos de Australia celebrada en el año 2002 y nos dice que debemos «hacer la experiencia de una conversión, de un cambio del corazón» ${ }^{17}$.

El papa Benedicto XVI, con ocasión del viII centenario de la conversión de san Francisco de Asís, dedicó precisamente su homilía para hablar sobre el tema de la conversión. El papa coloca tres modelos de convertidos: el rey David, el apóstol Pablo y san Francisco de Asís. En relación con este último, el pontífice destaca:

Esta es su conversión a Cristo, hasta el deseo de «transformarse» en él, llegando a ser su imagen acabada, que explica su manera típica de vivir, en virtud de la cual se nos presenta tan actual, incluso respecto de los grandes temas de nuestro tiempo, como la búsqueda de la paz, la salvaguardia de la naturaleza y la promoción del diálogo entre todos los hombres ${ }^{18}$.

Para el papa Benedicto XVI, san Francisco de Asís es un modelo imitable porque toda su obra y enseñanza parte de una conversión. Además, hace énfasis no solo en su entrega por los pobres sino por su profundo respeto y amor por los animales y la naturaleza. El mismo papa Francisco va a dedicar los números del 10 al 12 de Laudato si ' a este santo italiano y lo va a colocar como modelo de una ecología integral y resaltará su especial relación con la creación:

Él entraba en comunicación con todo lo creado, y hasta predicaba a las flores «invitándolas a alabar al Señor, como si gozaran del don de la razón». Su reacción era mucho más que una valoración intelectual o un cálculo económico, porque para él cualquier criatura era una hermana, unida a él con lazos de cariño. Por eso se sentía llamado a cuidar todo lo que existe. Su discípulo san Buenaventura decía de él que, «lleno de la mayor ternura al considerar el origen común de todas las cosas, daba a todas las criaturas, por más despreciables que parecieran, el dulce nombre de hermanas». Esta convicción no puede ser despreciada como un romanticismo irracional, porque tiene consecuencias en las

17 Francisco, Carta Encíclica Laudato Si' sobre el cuidado de la casa común, n. 218.

18 Visita pastoral de su santidad Benedicto XVI a Asís con ocasión del VIII centenario de la conversión de San Francisco, 17 de junio de 2007, consultada en marzo 10, 2017, https://w2.vatican.va/content/ benedict-xvi/es/homilies/2007/documents/hf_ben-xvi_hom_20070617_assisi.html. 
opciones que determinan nuestro comportamiento. Si nos acercamos a la naturaleza y al ambiente sin esta apertura al estupor y a la maravilla, si ya no hablamos el lenguaje de la fraternidad y de la belleza en nuestra relación con el mundo, nuestras actitudes serán las del dominador, del consumidor o del mero explotador de recursos, incapaz de poner un límite a sus intereses inmediatos ${ }^{19}$.

Frente a este sucinto análisis queda claro que incluir dentro de la conversión el aspecto ecológico no se trata de una moda, sino que «implica dejar brotar todas las consecuencias de nuestro encuentro con Jesucristo en las relaciones con el mundo que nos rodea. Vivir la vocación de ser protectores de la obra de Dios es parte esencial de una existencia virtuosa, no consiste en algo opcional ni en un aspecto secundario de la experiencia cristiana $»^{20}$.

Además, cuando hablamos de ecología no estamos hablando de un movimiento verde con tonalidad turística, ni simplemente de un movimiento que busca preservar las especies en extinción sino, en palabras de Juan José Tamayo:

Se trata de una nueva cosmovisión con una profunda inspiración ética y religiosa, que cuestiona de manera radical el modelo de civilización tecno-científica imperante y propone un paradigma alternativo capaz de salvaguardar armónicamente los derechos de la naturaleza y los de la humanidad ${ }^{21}$.

Frente a esta concepción de la ecología el mismo Tamayo se plantea una serie de preguntas que resultan muy pertinentes aquí: ¿Hay lugar para la ecología en el discurso teológico?, ¿tiene la teología un horizonte ecológico?, ¿hay lugar para la teología en el discurso ecológico? Si lo hay, żtiene algo que aportar?, ¿̇pueden ambos discursos compaginarse sin sufrir violencia, o cada uno debe seguir su camino independiente? ${ }^{22}$. Sería pretensioso responder de manera amplia a cada uno de estos interrogantes, pero la categoría conversión puede aportar no solo a la hora de generar el diálogo

19 Francisco, Carta Encíclica Laudato $\mathrm{Si}^{\prime}$ sobre el cuidado de la casa común, n. 11.

20 Francisco, Carta Encíclica Laudato Si' sobre el cuidado de la casa común, n. 217.

21 Juan José Tamayo, Nuevo paradigma teológico (Madrid: Editorial Trotta 2004), 113.

22 Juan José Tamayo, Nuevo paradigma teológico, 114. 
entre la teología y la ecología, sino de suscitar una respuesta a la crisis socio-ambiental por la que estamos pasando. Ahora pasaré a describir el origen del concepto de conversión ecológica.

\subsection{Orígenes del concepto de conversión ecológica}

Este término ha entrado a formar parte de la Doctrina Social de la Iglesia y en general se coincide que fue acuñado por el papa Juan Pablo II y se refiere a una relación significativamente modificada con el medio ambiente ${ }^{23}$. La expresión «conversión ecológica» fue utilizada por los obispos de Lombardía (1998), Islas Baleares (1990), Estados Unidos (1991), Brasil (1992), Alemania (1997) y la República Checa (2000), antes de que Juan Pablo II la usara ${ }^{24}$. Sin embargo, en innegable que será el pontífice polaco el que profundizará en el sentido del concepto. En el mensaje para la Jornada Mundial de la Paz de 1990, que se titula, Paz con Dios creador, paz con toda la creación, Juan Pablo II manifiesta que la paz mundial está amenazada no solo por la carrera armamentística, por los conflictos regionales o las injusticias aún existentes en muchos pueblos, sino también por la falta del debido respeto a la naturaleza, la explotación desordenada de sus recursos y el deterioro progresivo de la calidad de vida.

Estas ideas serán profundizadas en el mensaje y gran parte del mismo será dedicado precisamente a una serie de temas relacionados con el medio ambiente, tales como: la conciencia ecológica ${ }^{25}$, la relación entre la actuación humana y la integridad de la creación ${ }^{26}{ }_{\text {, }}$ el deterioro ambiental ${ }^{27}$, la crisis ecológica como un problema moral ${ }^{28}$, entre otros. Aunque no encontramos en el documento una alusión literal al concepto conversión ecológica, si hace un llamado a que

23 Ormerod Neil y Vanin Cristina, «Ecological conversion: ¿What Does it Mean?», Theological Studies 77 (2016): 328-352.

24 Tatay Nieto, De la cuestión social a la cuestión socio-ambiental. Implicaciones de Laudato si' para la DSI (Santander: Sal Terrae, 2015), 182.

25 Juan Pablo II, Mensaje para la Jornada Mundial de la Paz de 1990, n. 1.

26 Juan Pablo II, Mensaje para la Jornada Mundial de la Paz de 1990, n. 2.

27 Juan Pablo II, Mensaje para la Jornada Mundial de la Paz de 1990, n. 5.

28 Juan Pablo II, Mensaje para la Jornada Mundial de la Paz de 1990, n. 6-7. 
revisemos seriamente como sociedades nuestro estilo de vida ${ }^{29} \mathrm{y}$ además manifiesta:

Hay pues una urgente necesidad de educar en la responsabilidad ecológica: responsabilidad con nosotros mismos y con los demás, responsabilidad con el ambiente. Es una educación que no puede basarse simplemente en el sentimiento o en una veleidad indefinida. Su fin no debe ser ideológico ni político, y su planteamiento no puede fundamentarse en el rechazo del mundo moderno o en el deseo vago de un retorno al "paraíso perdido». La verdadera educación de la responsabilidad conlleva una conversión auténtica en la manera de pensar y en el comportamiento ${ }^{30}$.

El texto termina con un llamado muy serio a la responsabilidad de todos los cristianos en relación con el cuidado y respeto del medio ambiente:

Al final de este Mensaje deseo dirigirme directamente a mis hermanos y hermanas de la Iglesia católica para recordarles la importante obligación de cuidar toda la creación. El compromiso del creyente por un ambiente sano nace directamente de su fe en Dios creador, de la valoración de los efectos del pecado original y de los pecados personales, así como de la certeza de haber sido redimido por Cristo. El respeto por la vida y por la dignidad de la persona humana incluye también el respeto y el cuidado de la creación, que está llamada a unirse al hombre para glorificar a Dios (cfr. Sal 148 y 96$)^{31}$.

En la audiencia general del 17 de enero de 2001 encontramos una alusión directa al concepto de conversión ecológica. El papa Juan Pablo II dedica esta audiencia al tema del compromiso por evitar la catástrofe ecológica. Manifiesta que el hombre ha recibido una misión de gobierno sobre la creación, pero esta misión no debe entenderse como la de un dueño absoluto, sino como la de un administrador del reino de Dios, llamado a continuar la obra del Creador, una obra de vida y de paz $^{32}$. Sin embargo, continúa el pontífice polaco, el hombre ha defraudado esta misión divina, nos dice:

29 Juan Pablo II, Mensaje para la Jornada Mundial de la Paz de 1990, n. 13.

30 Juan Pablo II, Mensaje para la Jornada Mundial de la Paz de 1990, n. 13. (La cursiva es mía)

31 Juan Pablo II, Mensaje para la Jornada Mundial de la Paz de 1990, n. 16.

32 Juan Pablo II, Audiencia General, n. 3. 
Sobre todo en nuestro tiempo, el hombre ha devastado sin vacilación llanuras y valles boscosos, ha contaminado las aguas, ha deformado el hábitat de la tierra, ha hecho irrespirable el aire, ha alterado los sistemas hidro-geológicos y atmosféricos, ha desertizado espacios verdes, ha realizado formas de industrialización salvaje, humillando -con una imagen de Dante Alighieri (Paraíso, XXII, 151)- el «jardín» que es la tierra, nuestra morada ${ }^{33}$.

En este contexto que el mismo papa llama catastrófico es que introduce el llamado a una conversión ecológica: «Es preciso, pues, estimular y sostener la "conversión ecológica", que en estos últimos decenios ha hecho a la humanidad más sensible respecto a la catástrofe hacia la cual se estaba encaminando. El hombre no es ya "ministro" del Creador. Pero, autónomo déspota, está comprendiendo que debe finalmente detenerse ante el abismo» ${ }^{34}$. Para el Papa, uno de los caminos para detener la forma en que estamos depredando el planeta es precisamente el de la conversión que es parte fundamental del compromiso de todos por cuidar la creación y responder con coherencia a la misión divina que hemos recibido.

Un año más tarde, más exactamente el 10 de junio de 2002, aparece la llamada Declaración de Venecia que es una declaración conjunta del papa Juan Pablo II y el patriarca ecuménico Bartolomé $\mathrm{I}^{35}$. El objetivo de esta declaración ecuménica es llamar la atención sobre dos problemáticas que se han ido acentuando al inicio del tercer milenio. Por un lado, el sufrimiento diario de gran número de personas a causa de la violencia, el hambre, la pobreza y la enfermedad. Y, por otro lado, las consecuencias negativas que se derivan de la degradación de los recursos naturales. En relación con el segundo aspecto, el texto hace una invitación a que se respete la creación y a que se estimule una verdadera conciencia ecológica, que la entiende como la responsabilidad de nuestros actos con respecto a nosotros

33 Juan Pablo II, Audiencia General, n. 4.

34 Juan Pablo II, Audiencia General, n. 5.

35 Cf. Juan Pablo II y Bartolomé I, Firma de la Declaración de Venecia, consultada en marzo 10, 2017, https://w2.vatican.va/content/john-paul-ii/es/speeches/2002/june/documents/hf_jp-ii_spe_20020610_ venice-declaration.html. 
mismos, con respecto a los demás y con respecto a la creación. Y en este sentido hace un llamado al arrepentimiento y a la conversión:

Hace falta un acto de arrepentimiento por nuestra parte y un nuevo intento de mirarnos a nosotros mismos, a los demás y al mundo que nos rodea desde la perspectiva del designio divino de la creación. El problema no es solamente económico y técnico, sino también moral y espiritual. Una solución a nivel económico y técnico solo es posible si realizamos, del modo más radical, un cambio interior de corazón, que lleve a un cambio del estilo de vida y de los modelos insostenibles de consumo y producción. Una conversión auténtica en Cristo nos permitirá cambiar nuestro modo de pensar y actuar ${ }^{36}$.

Es interesante resaltar cómo para ambos líderes religiosos la solución a los problemas ambientales por los que está pasando el planeta no solo depende de lo político, económico o técnico, sino que se encuentra en el interior del hombre. $Y$, en este sentido, la conversión de nuestro estilo de vida por otro que afecte menos al planeta es necesario, no solo para los hombres de hoy, sino para las futuras generaciones.

Podríamos citar también la Exhortación apostólica postsinodal Pastores gregis, de Juan Pablo II, que hace una invitación a los obispos a que dentro de sus tareas propendan por el respeto al medioambiente y el cuidado de la creación. Y en este punto los llama también a que contribuyan al tema de la conversión ecológica:

Se necesita, pues, una conversión ecológica, a la cual los Obispos darán su propia contribución enseñando la relación correcta del hombre con la naturaleza. Esta relación, a la luz de la doctrina sobre Dios Padre, creador del cielo y de la tierra, es de tipo «ministerial». En efecto, el hombre ha sido puesto en el centro de la creación como ministro del Creador ${ }^{37}$.

Además de los documentos del papa Juan Pablo II vale la pena tener en cuenta el documento de los obispos canadienses de la Commission for Social Affairs, titulado: Our relationship with the environment: the need for conversion. En dicho documento de 2008,

37 Juan Pablo II, Exhortación apostólica postsinodal Pastores Gregis, n. 70. 
la Conferencia de Obispo del Canadá desarrolla la riqueza del concepto conversión y específicamente relacionado con la naturaleza. Es un interesante llamado de atención para que pensemos que los recursos del planeta son limitados y, por tanto, no podemos seguir consumiendo y gastando recursos como si fueran infinitos. Además, hacen énfasis en la conversión ecológica como la posibilidad de liberarnos como sociedades de nuestra obsesión por el poseer y el consumir y miremos la naturaleza con nuevos ojos. No como una despensa de la cual tomamos lo que necesitamos, sino como una creación de Dios que nos sustenta y nos brinda su belleza ${ }^{38}$.

\section{La conversión ecológica en el papa Francisco}

El tema de la conversión ecológica aparece desarrollado en el capítulo 6 de la encíclica ${ }^{39}$. En un documento tan extenso como este parece que fuera muy breve el espacio que se le dedica al tema. Sin embargo, si miramos con atención el documento pontificio nos encontramos que desde los numerales iniciales se hace referencia al concepto. En los numerales del 3 al 6, el papa Francisco hace un sucinto recuento de los aportes y reflexiones de sus predecesores en relación con el tema ecológico. Y, específicamente, en el numeral 5 recuerda que Juan Pablo II hizo un llamado a una conversión ecológica global $^{40}$.

Francisco, en el numeral 8, desarrolla los aportes que Bartolomé, Patriarca Ecuménico de Constantinopla, ha realizado sobre temas ecológicos:

1. El llamado que hace a que todos los seres humanos nos arrepintamos de la forma en que estamos dañando el planeta;

2. Los pecados contra la creación;

38 Cf. Commission for Social Affairs, Our relationship with the environment: the need for conversion, consultada en marzo 10, 2017, http://www.cccb.ca/site/images/stories/pdf/enviro_eng.pdf.

39 Cf. Francisco, Carta Encíclica Laudato Si' sobre el cuidado de la casa común, n. 216-221.

40 Francisco, Carta Encíclica Laudato $\mathrm{Si}^{\prime}$ sobre el cuidado de la casa común, n. 5. 
3. Las raíces éticas y espirituales de los problemas ambientales que nos invitan a encontrar soluciones no solo en la técnica sino en un cambio del ser humano.

El Papa resalta, en los aportes del Patriarca, un verdadero llamado a que reconozcamos que con nuestras acciones y en la forma que nos hemos organizado como sociedades le estamos haciendo un daño inmenso al planeta. Este daño se puede expresar con el concepto «pecado contra la creación»y ante el pecado debemos buscar la reconciliación que exige una conversión y en este sentido podríamos hablar de una conversión ecológica ${ }^{41}$.

El capítulo 6 de Laudato si ' se centra en dos líneas de acción que propone el papa en relación con la crisis socio-ambiental por la que estamos pasando: la educación y la espiritualidad ecológica. Desde un inicio del capítulo, el papa es consciente que debemos cambiar, reorientar muchas cosas como humanidad ${ }^{42}$ y dentro de esos aspectos se destacan: apostar por otro estilo de vida, una educación para la alianza entre la humanidad y el ambiente y la conversión ecológica. Estos tres aspectos se inspiran en «el tesoro de la experiencia espiritual cristiana ${ }^{43}$. Veamos brevemente estos elementos ya que los tres están íntimamente integrados:

a) Apostar por otro estilo de vida: Si lo que necesitamos es reorientar el rumbo que llevamos como sociedades y que está produciendo una crisis socio-ambiental, es fundamental que analicemos muy seriamente nuestro estilo de vida y en lo posible lo cambiemos. Nuestro estilo de vida actual, según el papa Francisco, está centrado en un elemento cardinal del sistema económico: el consumo. Si queremos apostar por otro estilo de vida, lo primero sería atacar el consumo. El papa Benedicto XVI afirmaba: «Comprar es siempre un acto moral, y no solo económico» ${ }^{44}$. Pero el pontífice

41 Cf. Francisco, Carta Encíclica Laudato Si' sobre el cuidado de la casa común, n. 8.

42 Cf. Francisco, Carta Encíclica Laudato Si' sobre el cuidado de la casa común, n. 202.

43 Francisco, Carta Encíclica Laudato Si'sobre el cuidado de la casa común, n. 15.

44 Benedicto XVI, Carta encíclica Caritas in veritate, n. 206, consultada en marzo 10, 2017, http://w2.vatican. va/content/benedict-xvi/es/encyclicals/documents/hf_ben-xvi_enc_20090629_caritas-in-veritate.html. 
sudamericano advierte sobre una paradoja, pues, aunque todos tenemos la libertad de consumir, en realidad es un privilegio que en general lo ejercen con mayor libertad los que sustentan el poder económico. Independientemente, este es un primer elemento que es necesario reorientar. Muy unido a lo anterior el papa Francisco destaca el predominio del individualismo que nos vuelve indiferentes hacia los otros y hacia la creación. Sin embargo, en este primer aspecto el pontífice no cae en el pesimismo, sino que es optimista frente a los seres humanos:

Sin embargo, no todo está perdido, porque los seres humanos, capaces de degradarse hasta el extremo, también pueden sobreponerse, volver a optar por el bien y regenerarse, más allá de todos los condicionamientos mentales y sociales que les impongan. Son capaces de mirarse a sí mismos con honestidad, de sacar a la luz su propio hastío y de iniciar caminos nuevos hacia la verdadera libertad. No hay sistemas que anulen por completo la apertura al bien, a la verdad y a la belleza, ni la capacidad de reacción que Dios sigue alentando desde lo profundo de los corazones humanos. A cada persona de este mundo le pido que no olvide esa dignidad suya que nadie tiene derecho a quitarle ${ }^{45}$.

b) Educación para la alianza entre la humanidad y el ambiente: el papa Francisco manifiesta que es necesario un desafío educativo ${ }^{46}$. Un desafío que debe incluir una educación ambiental que no se debe quedar simplemente en un diagnóstico técnico de los problemas por los cuales estamos pasando, sino que tiene que conducirnos al Misterio y en donde no solo se informe, sino que se cree hábitos. Aquí el papa coloca ejemplos muy concretos, que vale la pena mencionar:

Es muy noble asumir el deber de cuidar la creación con pequeñas acciones cotidianas, y es maravilloso que la educación sea capaz de motivarlas hasta conformar un estilo de vida. La educación en la responsabilidad ambiental puede alentar diversos comportamientos que tienen una incidencia directa e importante en el cuidado del ambiente, como evitar el uso de material plástico y de papel, reducir el consumo de agua, separar los residuos, cocinar solo lo que razonablemente se podrá comer, tratar con cuidado a los demás seres vivos, utilizar transporte público o compartir un

45 Francisco, Carta Encíclica Laudato Si' sobre el cuidado de la casa común, n. 205.

46 Francisco, Carta Encíclica Laudato $\mathrm{Si}^{\prime}$ sobre el cuidado de la casa común, n. 209. 
mismo vehículo entre varias personas, plantar árboles, apagar las luces innecesarias. Todo esto es parte de una generosa y digna creatividad, que muestra lo mejor del ser humano. El hecho de reutilizar algo en lugar de desecharlo rápidamente, a partir de profundas motivaciones, puede ser un acto de amor que exprese nuestra propia dignidad ${ }^{47}$.

En este punto de la educación ambiental el papa hace un llamado a la familia, pues la familia es el lugar de formación integral ${ }^{48}$. Si se educa desde la familia con el apoyo de la escuela podemos crear verdaderos «ciudadanos ecológicos» que se comprometan con el respeto a la vida y el cuidado de la creación. Una educación de este tipo tiene la capacidad de contrarrestar el paradigma consumista que se transmite por los medios de comunicación y que respiramos a diario en nuestra sociedad.

c) La conversión ecológica: tanto el cambio en nuestro estilo de vida como una educación ambiental nos llevan a la conversión. La crisis ecológica, dice el papa Francisco, es un llamado a una profunda conversión interior. Esta conversión ecológica tiene unos elementos que brevemente vamos a describir:

- Nace de un encuentro con Jesucristo que exige de nosotros ser protectores de la obra de Dios. Esta llamada no es un aspecto opcional o secundario de la experiencia cristiana, sino de primero orden y esencial ${ }^{49}$. La cuestión ecológica es una dimensión constitutiva del discipulado cristiano ${ }^{50}$.

- Necesidad de reconocer los propios pecados que hemos cometido contra la creación y arrepentirnos de corazón para empezar a transitar por una verdadera conversión ecológica ${ }^{51}$.

- Esta conversión ecológica no solo se debe realizar de forma individual sino también comunitaria. Se necesita que unamos

\footnotetext{
47 Francisco, Carta Encíclica Laudato Si' sobre el cuidado de la casa común, n. 211.

48 Francisco, Carta Encíclica Laudato Si' sobre el cuidado de la casa común, n. 213.

49 Francisco, Carta Encíclica Laudato Si' sobre el cuidado de la casa común, n. 217.

50 Cf. Tobias Winright, Green Discipleship. Catholic Theological Ethics and the Environment (Winona: Anselm Academic, 2011).

51 Francisco, Carta Encíclica Laudato Si'sobre el cuidado de la casa común, n. 218.
} 
fuerzas y nos unamos como sociedades para que afrontemos y actuemos eficazmente frente a las problemáticas que se nos presentan. En palabras del papa Francisco: «La conversión ecológica que se requiere para crear un dinamismo de cambio duradero es también una conversión comunitaria» ${ }^{52}$.

- La conversión ecológica, además, exige de una serie de actitudes: gratitud y gratuidad, ternura, amorosa conciencia de no estar desconectados de las demás criaturas, creatividad y entusiasmo por parte de todos los creyentes para resolver los problemas ecológicos por los que estamos pasando, responsabilidad frente a la obra creadora de $\operatorname{Dios}^{53}$.

- Finalmente, hay una serie de convicciones de fe que ayudan a enriquecer el sentido de la conversión ecológica, tales como: la conciencia de que cada criatura refleja algo de Dios y tiene un mensaje que enseñarnos, la seguridad de que Cristo ha asumido en sí este mundo material y ahora, resucitado, habita en lo íntimo de cada ser, rodeándolo con cariño y el reconocimiento de que Dios ha creado el mundo inscribiendo en él un orden y un dinamismo que el ser humano no tiene derecho a ignorar ${ }^{54}$.

El papa Francisco, después de describir estos aspectos que son elementos cardinales de su comprensión de la conversión ecológica, hace un llamado muy especial:

Invito a todos los cristianos a explicitar esta dimensión de su conversión, permitiendo que la fuerza y la luz de la gracia recibida se explayen también en su relación con las demás criaturas y con el mundo que los rodea, y provoque esa sublime fraternidad con todo lo creado que tan luminosamente vivió san Francisco de Asís ${ }^{55}$.

Detrás de la crisis ecológica existen estructuras de pecado que la favorecen, pero también personas concretas que actúan y que,

55 Francisco, Carta Encíclica Laudato $\mathrm{Si}^{\prime}$ sobre el cuidado de la casa común, n. 221. 
de forma más o menos consciente, colaboran con tales estructuras y para lo que se necesita compromiso por la transformación, pero también conversión personal. Por eso la encíclica es un reto no solo para los agentes sociales, sino para cada persona concreta, porque «toda pretensión de cuidar y mejorar el mundo supone cambios profundos en los estilos de vida, los modelos de producción y de consumo, las estructuras consolidadas de poder que rigen hoy la sociedad $»^{56}$. En síntesis: la crisis medioambiental exige también un cambio en nuestra manera concreta de vivir, de decidir y de actuar en las pequeñas cosas de cada día. Ahí entra la conversión ecológica como importante factor de cambio.

Un último aspecto y no menos importante sobre la comprensión de la conversión ecológica en la encíclica Laudato si' del papa Francisco es que la conversión que él propone es una conversión a una ecología integral. El pontífice sudamericano, sobre todo en el primer capítulo de la encíclica, describe el mundo que hemos construido: grandes desigualdades, egoísmo de los ricos, políticas irresponsables, sobre todo en el uso de los recursos naturales, graves problemas ambientales que nosotros hemos causado. Para el Papa hay tres factores que están en el origen de esta situación:

1. La cultura del descarte ${ }^{57}$.

2. La producción y el consumo sin límites ${ }^{58}$.

3. La idolatrización de las ciencias técnicas ${ }^{59}$.

El papa Francisco exhorta a todos habitantes a un cambio en un estilo de vida, de modo que a todos les sea asegurado el derecho que poseen de respirar un aire puro, a beber un agua limpia, a beneficiarse de un trabajo digno. Se trata de una conversión: la conversión a una ecología integral.

56 Francisco, Carta Encíclica Laudato $\mathrm{Si}^{\prime}$ sobre el cuidado de la casa común, n. 5.

57 Cf. Francisco, Carta Encíclica Laudato $\mathrm{Si}^{\prime}$ sobre el cuidado de la casa común, n. 22.

58 Cf. Francisco, Carta Encíclica Laudato Si' sobre el cuidado de la casa común, n. 56.

59 Cf. Francisco, Carta Encíclica Laudato Si' sobre el cuidado de la casa común, n. 104 


\title{
4. La conversión ecológica: conversión de la mente, del corazón y de nuestro estilo de vida
}

Uno de los elementos que más se ha resaltado de la propuesta del papa Francisco en Laudato si ' tiene que ver con su comprensión de la crisis actual. Él nos recuerda que en realidad no estamos frente a dos crisis, una social y otra ambiental, sino ante una misma crisis socio-ambiental ${ }^{60}$. Leonardo Boff ya lo había insinuado en su libro de 1996, Ecología: grito de la tierra, grito de los pobres, donde escribió:

\begin{abstract}
Dos grandes problemas van a ocupar las mentes y los corazones de la humanidad aquí en adelante: ¿̇cuál será el destino y el futuro del planeta Tierra si prolongamos la lógica del pillaje a la que nos han acostumbrado el modelo de desarrollo y de consumo? ¿Cuál es la esperanza del mundo, de esos dos tercios de pobres de la humanidad? Existe el riesgo de que la «cultura de los satisfechos» se cierre en su egoísmo consumista e ignore cínicamente la devastación de las masas pobres del mundo. Como también existe el riesgo de que los «nuevos bárbaros» no acepten ese veredicto de muerte y se lancen a una lucha desesperada por la supervivencia, amenazándolo todo y destruyéndolo todo. A menos que colectivamente decidamos cambiar el curso de la civilización, desplazar de su eje la lógica de los medios al servicio de la acumulación excluyente y trasladarlo hacia una lógica de los fines en función del bienestar común del planeta Tierra, de los humanos y de todos los seres, en el ejercicio de la libertad y de la cooperación entre los pueblos ${ }^{61}$.
\end{abstract}

Frente a esta crisis socio-ambiental la conversión ecológica es una respuesta que se enmarca dentro de la espiritualidad cristiana. Como hemos desarrollado, la conversión la entendemos como el regreso a la casa del Padre abandonando el pecado no solo en sus dimensiones con Dios, con nosotros mismos y con los otros, sino también en su dimensión contra la creación y en esta última dimensión enmarcamos la conversión ecológica. Esta conversión exige la reconciliación, un cambio en nuestro estilo de vida, un respeto a nuestra casa común,

60 Cf. Francisco, Carta Encíclica Laudato Si' sobre el cuidado de la casa común, n. 139.

61 Leonardo Boff, Ecología: grito de la tierra, grito de los pobres, 146. 
una educación ambiental y una serie de convicciones de fe como la gratitud, la solidaridad y la contemplación.

En este sentido, el capítulo tercero de Laudato si' está dedicado a rastrear la raíz de la crisis ecológica. Para el papa Francisco la crisis ecológica tiene una raíz humana. El Papa concreta su análisis en lo que llama el paradigma tecnocrático, que ha conducido a un antropocentrismo desviado y despótico y que tiene como única solución que el ser humano recupere su lugar en el universo. Y una de estas soluciones exige que cambiemos nuestro estilo de vida. Para este nuevo estilo de vida el Papa propone como dos pilares. El primero es más universal: una «educación para la alianza entre la humanidad y el ambiente» ${ }^{62}$. El otro es más específicamente cristiano: una «conversión ecológica» que deriva de la fe cristiana ${ }^{63}$. La «conversión ecológica» exige una verdadera conversión de la mente, del corazón, del estilo de vida y de la solidaridad. Desde esta perspectiva estos elementos se convierten en verdaderas coordenadas, desde la fe cristiana, no solo para comprender la situación actual, sino para buscar alternativas frente a la crisis socio-ambiental por la que estamos pasando.

Podemos terminar este sucinto acercamiento a la conversión ecológica con un llamamiento que hace el papa Francisco a que nos responsabilicemos frente a nuestra casa común y que pensemos seriamente la forma en que nos estamos relacionando con ella:

¿Estamos verdaderamente cultivando y custodiando la creación? ¿̇O bien la estamos explotando y descuidando? Cultivar y custodiar la creación es una indicación de Dios dada no solo al inicio dela historia, sino a cada uno de nosotros; es parte de su proyecto; quiere decir hacer crecer el mundo con responsabilidad, transformarlo para que sea un jardín, un lugar habitable para todos ${ }^{64}$.

62 Francisco, Carta Encíclica Laudato Si' sobre el cuidado de la casa común, n. 209.

63 Cf. Francisco, Carta Encíclica Laudato $\mathrm{Si}^{\prime}$ sobre el cuidado de la casa común, n. 216 y ss.

64 Francisco, Audiencia General, miércoles 5 de junio de 2013, consultada en marzo 10, 2017, https:// w2.vatican.va/content/francesco/es/audiences/2013/documents/papa-francesco_20130605_udienzagenerale.html. 


\section{Conclusión}

La encíclica Laudato si ' es un verdadero llamado de atención en torno a los problemas ambientales que actualmente afectan nuestro planeta y una invitación para que nos unamos y hagamos algo antes de que sea demasiado tarde. Pero además de eso es un desafío para la misma teología, una teología que no puede estar al margen de esta problemática. El análisis que hace el papa Francisco no se reduce a describir la problemática ambiental que estamos viviendo y que hemos causado, va más allá. La encíclica no es solo un texto sobre el medio ambiente sino sobre modelos económicos, desarrollo, justicia, pobreza, entre otras cosas. Es un documento que quiere escuchar el grito de los pobres y el grito de la tierra. En palabras de Leonardo Boff:

La teología de la liberación y el discurso ecológico tienen algo en común: parten de dos heridas sangrantes. La primera, la herida de la pobreza y de la miseria, rompe el tejido social de los millones y millones de pobres en el mundo entero. La segunda, la agresión sistemática a la Tierra, desestructurada el equilibrio del planeta amenazado por la depredación hecha a partir del modelo de desarrollo planteado por las sociedades contemporáneas y hoy mundializadas ${ }^{65}$.

La fe cristiana en Dios creador nos hace vivir desde la experiencia del don (todo nos ha sido dado), la realidad entera adquiere un valor nuevo, cada cosa tiene un valor en sí misma. Y eso impide toda instrumentalización o uso ilimitado y despótico. Se trata de una verdadera «conversión ecológica», a la que puede contribuir la espiritualidad cristiana. A esta cuestión dedica Laudato si ' parte del último capítulo. Allí se habla de una espiritualidad ecológica ${ }^{66}$ que posibilita esa conversión y se traduce en actitudes ${ }^{67}$ y en convicciones. Entre estas últimas:

65 Leonardo Boff, Ecología: grito de la tierra, grito de los pobres, 135.

66 Cf. Francisco, Carta Encíclica Laudato Si 'sobre el cuidado de la casa común, n. 216

67 Cf. Francisco, Carta Encíclica Laudato Si' sobre el cuidado de la casa común, n. 220. 
La conciencia de que cada criatura refleja algo de Dios y tiene un mensaje que enseñarnos, o la seguridad de que Cristo ha asumido en sí este mundo material y ahora, resucitado, habita en lo íntimo de cada ser, rodeándolo con su cariño y penetrándolo con su luz. También el reconocimiento de que Dios ha creado el mundo inscribiendo en él un orden y un dinamismo que el ser humano no tiene derecho a ignorar ${ }^{68}$.

Todo ello se plasma en un modo alternativo de entender la calidad de vida y un estilo de vida profético y contemplativo, dos dimensiones que no siempre se suelen dar juntas. Profético, frente a la obsesión del consumo que nos domina; contemplativo, porque permite hacerse presente serenamente ante cada realidad, por pequeña que sea, lo que nos abre muchas más posibilidades de comprensión y de realización personal ${ }^{69}$.

En este sentido podemos enmarcar la sistematización que hemos tratado de hacer de la conversión ecológica. No se trata de agregar un apelativo a la larga tradición de la Iglesia sobre el tema de la conversión. La conversión ecológica no es solo un cambio individual de actitudes frente a la depredación que estamos haciendo con el planeta, también es un cambio de estructuras. Estructuras que cosifican al ser humano, que crean grandes desigualdades; estructuras que posibilitan la pobreza, que permiten que millones de seres humanos, especialmente niños, mueran de hambre todos los días; estructuras que han convertido al ser humano en un simple servidor del dinero y, finalmente, estructuras que están convirtiendo al planeta en un «inmenso depósito de porquería» ${ }^{70}$ y en donde peligra no solo nuestra supervivencia sino la de miles de especies que comparten con nosotros esta casa común.

Realmente, tendremos una conversión ecológica como individuos y como sociedades, cuando cambiemos el rumbo y pensemos más en nuestra hermana y madre Tierra y en el grito de millones de seres humanos que viven en la pobreza. Esta conversión

68 Francisco, Carta Encíclica Laudato $\mathrm{Si}^{\prime}$ sobre el cuidado de la casa común, n. 221.

69 Cf. Francisco, Carta Encíclica Laudato Si' sobre el cuidado de la casa común, n. 222

70 Francisco, Carta Encíclica Laudato Si'sobre el cuidado de la casa común, n. 21. 
solo se entiende en un encuentro con Jesucristo ${ }^{71}$ y representa para los cristianos una exigencia de fe a la altura de los tiempos que estamos viviendo.

\section{Bibliografía}

Benedicto XVI. Carta encíclica Caritas in veritate. Consultada en marzo 10, 2017. http://w2.vatican.va/content/benedict-xvi/ es/encyclicals/documents/hf_ben-xvi_enc_20090629_caritas-in-veritate.html.

Benedicto XVI. Homilía en el solemne inicio del ministerio petrino. Consultada en marzo 10, 2017. https://w2.vatican.va/ content/benedict-xvi/es/homilies/2005/documents/hf_benxvi_hom_20050424_inizio-pontificato.html.

Boff, Leonardo. La dignidad de la Tierra. Ecología, mundialización, espiritualidad. La emergencia de un nuevo paradigma. Madrid: Trotta, 2000.

Boff, Leonardo. Ecología: grito de la tierra, grito de los pobres. Madrid: Trotta, 1996.

Boff, Leonardo. La Tierra está en nuestras manos. Una nueva visión del planeta y de la humanidad. Santander: Sal Terrae, 2016.

Camacho, Ildefonso. "Laudato si ' : el clamor de la tierra y el clamor de los pobres. Una encíclica más que ecológica». Revista de Fomento Social 71 (2016): 59-79.

Castillo, Daniel. «Integral ecology as a liberationist concept». Theological Studies 77 (2016): 353-376.

Catecismo de la Iglesia Católica. Consultada en marzo 10, 2017, http://www.vatican.va/archive/catechism_sp/index_sp.html.

71 Francisco, Carta Encíclica Laudato Si' sobre el cuidado de la casa común, n. 17. 
Conferencia de los Obispos católicos de Australia. A New Earth - The Environmental Challenge 2002. Consultada en marzo 10, 2017. http://www.socialjustice.catholic.org.au/files/SJSandresources/2002_SJSS_statement.pdf.

Costa y Foglizzo. «L'ecologia integrale». Aggiornamenti Sociali 66 (2015): 541-548.

Chica Arellano, Fernando y Granados García, Carlos, eds. Loado seas, mi señor. Comentario a la encíclica Laudato si' del papa Francisco. Madrid: BAC, 2016.

Francisco. Audiencia General, miércoles 5 de junio de 2013. Consultada en marzo 10, 2017. https://w2.vatican.va/content/ francesco/es/audiences/2013/documents/papa-francesco_20130605_udienza-generale.html.

Francisco. Carta Encíclica Laudato Si'. Sobre el cuidado de la casa común. Consultada en marzo 10, 2017. http://w2.vatican. $\mathrm{va} /$ content/francesco/es/encyclicals/documents/papa-francesco_20150524_enciclica-laudato-si.html.

Juan Pablo II. Exhortación apostólica Postsinodal Reconciliatio et paenitentia. Consultada en marzo 10, 2017. http://w2.vatican. va/content/john-paul-ii/es/apost_exhortations/documents/ hf_jp-ii_exh_02121984_reconciliatio-et-paenitentia.html.

Juan Pablo II. Mensaje para la Jornada Mundial de la Paz de 1990. Consultada en marzo 10, 2017. https://w2.vatican.va/ content/john-paul-ii/es/messages/peace/documents/hf_jpii_mes_19891208_xxiii-world-day-for-peace.html.

Juan Pablo II. Audiencia General, miércoles 17 de enero de 2001. Consultada en marzo 10, 2017. https://w2.vatican.va/ content/john-paul-ii/es/audiences/2001/documents/hf_jpii_aud_20010117.html.

Juan Pablo II. Exhortación apostólica postsinodal Pastores Gregis. Consultada en marzo 10, 2017. http://w2.vatican.va/content/john-paul-ii/es/apost_exhortations/documents/hf_jpii_exh_20031016_pastores-gregis.html. 
Lacroix, Michel. El humanicidio. Ensayo de una moral planetaria. Santader: Sal Terrae, 1995.

Lonergan, Bernard. Método en Teología. Salamanca: Sígueme, 1988.

Martínez, Julio Luis. Laudato si y y la cuestión socio-ambiental. Clamor de la Tierra y de los pobres. Santander: Sal Terrae, 2015.

Masía, Juan, ed. Hacia un ecoevangelio. El llamado ecológico de los papas Benedicto y Francisco. Barcelona: Herder, 2015.

Nature 522 (25 de junio de 2015): 391. Consultada en marzo 10, 2017. http://www.nature.com/news/hope-from-the-pope-1.17824.

Nieto, Tatay. De la cuestión social a la cuestión socio-ambiental. Implicaciones de Laudato si' para la DSI. Santander: Sal Terrae, 2015.

Ormerod, Neil y Vanin, Cristina. «Ecological conversion: What Does it Mean?». Theological Studies 77 (2016): 328-352.

Sallie, MacFague. Modelos de Dios. Teología para una era ecológica y nuclear. Santander: Sal Terrae, 1994.

Sanz Giménez-Rico, Enrique, ed. Cuidar de la Tierra, cuidar de los pobres. Laudato si' desde la teología y con la ciencia. Santander: Sal Terrae, 2015.

Tamayo Acosta, Juan José. Nuevo paradigma teológico. Madrid: Editorial Trotta, 2004.

Visita pastoral de su santidad Benedicto XVI a Asís con ocasión del viI centenario de la conversión de San Francisco, 17 de junio de 2007. Consultada en marzo 10, 2017. https:// w2.vatican.va/content/benedict-xvi/es/homilies/2007/documents/hf_ben-xvi_hom_20070617_assisi.html.

Winright, Tobias. Green Discipleship. Catholic Theological Ethics and the Environment. Winona: Anselm Academic, 2011. 